\title{
A ATIVIDADE DO PENSAR E A RELEVÂNCIA DO COMUNICAR NA E PARA A EDUCAÇÃO ESCOLAR: REFLEXÕES À LUZ DE HANNAH ARENDT
}

\author{
Jenerton Arlan Schütz ${ }^{1}$
}

\section{Resumo}

O presente artigo, de cunho bibliográfico, tem por objetivo tematizar a atividade de pensar e sua relação com o sentido do comunicar no âmbito educacional, a partir das reflexões de Hannah Arendt. Não obstante, uma maneira que temos para estabelecer um vínculo com este mundo é a atividade do pensar, o pensar é o que nos permite buscar significados e sentidos, para qual em outras esferas de nossa existência não é possível, ou não temos espaço e nem tempo. Todavia, para a educação escolar não basta apenas pensar sobre os acontecimentos e experiências que nos rodeiam, é preciso comunicar o que pensamos. É a partir do comunicar que entramos em contato com o pensar de outras pessoas, e é esse momento em que nossos alunos/recém-chegados são desafiados a pensar por conta própria, ou seja, começam a se indagar sobre a sua relação com os acontecimentos, com as demais pessoas e as coisas.

Palavras-Chave: Educar. Pensar. Comunicar.

\section{THE ACTIVITY OF THINKING AND THE RELEVANCE OF COMMUNICATING IN AND FOR SCHOOL EDUCATION: REFLECTIONS TO THE LIGHT OF HANNAH ARENDT}

\begin{abstract}
The aim of this article is to study the activity of thinking and its relationship with the meaning of communication in the educational sphere, based on Hannah Arendt reflections. Nevertheless, one way we have to establish a bond with this world is the activity of thinking, thinking is what allows us to seek meanings and senses, for which in other spheres of our existence it is not possible, or we do not have space nor time. However, for school education it is not enough to think about the events and experiences that surround us, we must communicate what we think. It is from the communication that we come in contact with the thinking of other people, and it is this moment in which our students / newcomers are challenged to think on their own, that is, they begin to inquire about their relation with events, with other people and things.
\end{abstract}

Keywords: Educating. Thinking. Communicating.

\footnotetext{
${ }^{1}$ Doutorando em Educação nas Ciências (UNIJUI), Mestre em Educação nas Ciências (UNIJUI), Especialista em Metodologia de Ensino de História pela Uniasselvi. Bolsista CAPES. Participa do grupo de estudo sobre: Teoria Crítica e Educação; Estudos Hermenêuticos e Teorias pedagógicas e dimensões éticas e políticas da educação do Mestrado e Doutorado em Educação nas Ciências (UNIJUí).
}

Criar Educação, Criciúma, v. 7, no1, jan/jul 2018.- PPGE - UNESC 


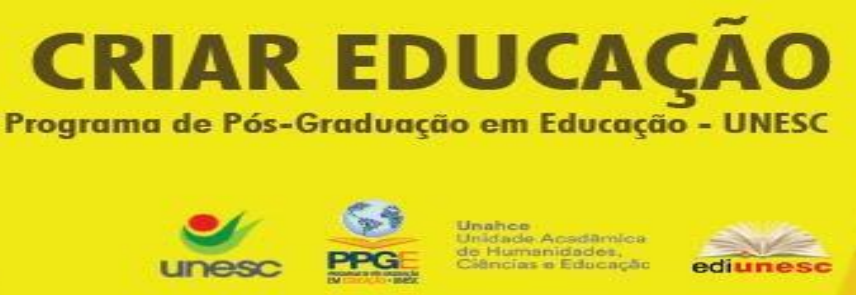

\section{INTRODUÇÃO}

Vivemos numa sociedade em que informação e tecnologia se tornam cada vez mais importantes, há uma enorme preocupação por parte da escola em buscar acompanhar o que denominamos de progresso científico e tecnológico. Sendo que, conhecimentos da geração denominada "mais velha", se mostram frente aos "mais novos" como conhecimentos obsoletos e que pouco tem a oferecer e contribuir em um mundo que está em constante mudança².

Assim, quando a nossa relação com o mundo, seja ela com o presente ou com o passado, não nos é simplesmente dada, precisamos identificar o que nós queremos apresentar aos recém-chegados, quais são as experiências, fatos, acontecimentos e pensamentos que possuem sentido e significado para nós, e que podem ser ressignificados pelos nossos alunos.

Contudo, é necessário indagarmos também sobre aquilo que não faz/tem sentido para nós, como os acontecimentos incompreensíveis (barbáries), e o que nós fazemos para nos reconciliar com este mundo, mesmo que este não seja como queiramos, devemos nos entender com ele. São os fatos que apresentam sentido e significado para nós que devemos apresentar aos recém-chegados, para opor à crescente ausência de sentido e referência, ou nos confrontamos de novo "com os problemas elementares da convivência humana." (ARENDT, 2013, p. 187).

Não obstante, uma maneira que temos para estabelecer um vínculo com este mundo é a atividade do pensar, isto é, o pensar é o que nos permite buscar significados e sentidos, para qual em outras esferas de nossa existência não é possível, ou não temos espaço e nem tempo. Nossa capacidade de relacionamento com os demais e a possibilidade de assumirmos a responsabilidade por aquilo que nos é comum, depende da nossa retirada temporária do mundo e do encontro com nós mesmos, ainda que isso não ocorra de forma imediata. Portanto, distanciamonos do mundo para buscar a compreensão da nossa experiência nele, lembramos os acontecidos e perguntamos qual é o sentido de tudo isso.

\footnotetext{
${ }^{2}$ Os fundamentos, a centralidade e a universalidade cedem lugar à arbitrariedade das combinações, à fragmentação das formas, ao disfarce e às máscaras, tudo se reduzindo a jogos de espelhos. Neutralizam-se as esperanças num contentamento superficial, sem grandes ganhos ou perdas de uma vida desprovida de eixo que a ordene, condenada a ilusões que a ninguém mais iludem. Tudo se torna indiferente num mundo onde nada mais faz sentido. (MARQUES, 1993, pp. 55-69).
}

Criar Educação, Criciúma, v. 7, no1, jan/jul 2018.- PPGE - UNESC 
Na mesma ocasião, Arendt (1993, p. 5, grifo nosso) se recusa a ser chamada de filósofa, pois,

Minha profissão, se é que se pode chamar assim, é a teoria política [...]. Para mim, o importante é compreender. Escrever é uma questão de procurar essa compreensão [...] o importante é o processo de pensar. Se consigo expressar de modo razoável meu processo de pensamento por escrito, isso me deixa satisfeita.

Arendt dedica-se na última fase de sua vida - mais preciso na década de 1970 - a um tema filosófico denominado de: as faculdades do espírito, atividades realizadas no momento em que se está só e, por isso, são atividades invisíveis aos olhos do mundo.

Uma experiência ocorrida em 1961, quando Arendt assiste ao julgamento de Adolf Eichmann, nazista que foi um dos principais responsáveis pela "solução final"." Hannah Arendt é enviada pela revista New Yorker para acompanhar esse julgamento e escreve um relatório que posteriormente é publicado como livro, denominado Eichmann em Jerusalém [1963]. E, a partir desse momento, Arendt volta seu olhar ao ser humano no singular, mas sem se esquecer que ele existe sob condição de pluralidade. Pois, "é no momento em que se chega ao indivíduo, e a pergunta a ser feita não é mais: Como esse sistema funciona?, mas: Por que o réu se tornou funcionário dessa organização?." (ARENDT, 2004, p. 121).

No decorrer do julgamento, Arendt se indaga como um ser humano pôde ser capaz de cometer tais monstruosidades. Ela se surpreende por Eichmann ser uma pessoa comum, para a Arendt (2004) não havia maldade naquela pessoa, uma vez que ele apenas tinha cumprido sua função. Mas, o que realmente chamou a atenção de Arendt, foi a incapacidade de Eichmann refletir sobre o acontecido e de pensar sobre o significado de seus atos. ${ }^{6}$

Tudo isso leva Arendt (1993, pp. 6-7) a se perguntar:

Será possível que o problema do bem e do mal [...] esteja conectado com a nossa faculdade de pensar? [...] seria possível que a atividade do pensamento como tal [...] estivesse dentre as condições que levam os

\footnotetext{
${ }^{5}$ Termo nazista que se referia ao extermínio dos judeus.

${ }^{6}$ Ainda em relação aos nazistas, para cometer atrocidades, foram capazes de aplicar tecnologias e conhecimentos avançados, ou mesmo produzir conhecimentos novos, mas foram incapazes de refletir sobre aquilo que estavam fazendo (ALMEIDA, 2011).
}

Criar Educação, Criciúma, v. 7, no1, jan/jul 2018.- PPGE - UNESC 
homens a se absterem de fazer o mal, ou mesmo que ela realmente os "condicione" contra ele?

A partir da experiência com Eichmann, podemos perceber que, apesar do pensamento se localizar fora do mundo, ele é fundamental para a nossa ação no mundo, assim, o olhar e a preocupação da autora se voltam para as atividades do espírito. E, uma das principais preocupações da autora se refere a essa atividade do pensamento, atividade que é exercida em um distanciamento do mundo, mas ao mesmo tempo precisa assumir a responsabilidade por ele e se relacionar com ele. Assim, como podemos responder ao mundo não só "a partir das nossas ações, mas também em nossa reflexão?" (ALMEIDA, 2011, p. 151).

Para a autora, é necessário se distanciar temporariamente do mundo e dos outros para permanecer, por um momento na presença de nós mesmos, essa é a atividade do pensar. A retirada do mundo das aparências é essencial para o pensamento (ARENDT, 1993). O pensar parte da experiência concreta, mas necessita distanciar-se da experiência para submetê-la à reflexão, ou segundo Arendt (1993), precisamos "parar para pensar", pois, "nunca um homem está mais ativo do que quando nada faz, nunca está menos só do que quando a sós consigo mesmo." (ARENDT, 1993, p. 5). Cabe aqui ainda a relação com os regimes totalitários, os quais, não pensaram, já que não pararam para se perguntar sobre o sentido e o significado do que estavam fazendo, isso para com as vítimas e com o mundo.

No momento em que estamos sozinhos ${ }^{7}$, é possível exercer um diálogo entre eu e eu mesmo (ARENDT, 1993), esse modo de nos retirarmos do mundo, diz respeito à "condição paradoxal de um ser vivo que [...] tem [...] a habilidade de pensar, que permite ao espírito retirar-se do mundo, sem jamais poder deixa-lo ou transcendê-lo." (ARENDT, 1993, p. 36).

Ademais, o pensar é o que nos permite buscar significados e sentidos, para qual em outras esferas de nossa existência não é possível, ou não temos espaço e nem tempo. Nossa capacidade de relacionamento com os demais e a possibilidade de assumirmos a responsabilidade por aquilo que nos é comum, depende da nossa retirada temporária do mundo e do encontro com nós mesmos, ainda que isso não

\footnotetext{
7 "Sempre que pensamos, interrompemos qualquer outra coisa que poderíamos estar fazendo [...]." (ARENDT, 2004, p. 170). A autora diferencia o estar só (apesar de estar sozinho, estou na companhia de mim mesmo), da solidão (experiência de abandono, o que foi a essência do totalitarismo) (ARENDT, 2004).
}

Criar Educação, Criciúma, v. 7, no1, jan/jul 2018.- PPGE - UNESC 


\section{CRIAR EDUCAÇÃO \\ Revista do Programa de Pós-Graduação em Educação - UNESC

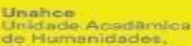 \\ ediunesc}

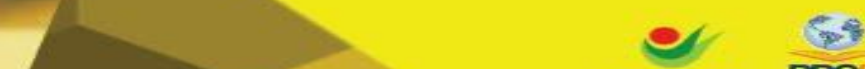

ocorra de forma imediata. Portanto, distanciamo-nos do mundo para buscar a compreensão da nossa experiência nele, lembramos os acontecidos e perguntamos qual é o sentido de tudo isso.

Para Almeida (2011, p. 155), "Qual seria a importância dessa faculdade do espírito que não é (apenas) um meio para produzir ou adquirir conhecimentos e habilidades, nem planejar ações e que não produz resultados diretamente úteis para nosso dia a dia e que, apesar disso, é constitutiva para nós enquanto seres humanos?". Para essa pergunta, Arendt nos apresenta uma resposta muito clara: a importância do pensar não reside nos resultados que produz, mas na própria atividade do pensar.

[...] a necessidade de pensar jamais pode ser satisfeita por insights ${ }^{8}$ supostamente preciosos de 'homens sábios'. Essa necessidade só pode ser satisfeita pelo próprio pensamento, e os pensamentos que ontem tive irão satisfazer essa necessidade, hoje, apenas porque quero e porque sou capaz de pensá-los novamente. (ARENDT, 1993, p. 69).

Ainda para a autora, o pensamento seria como o mito de Penélope, uma vez que: "o pensamento é como a teia [...], desfaz-se toda manhã o que se terminou de fazer na noite anterior." (ARENDT, 1993, p. 69). É o pensar que para Arendt importa mais do que os pensamentos, a atividade é mais importante que os resultados. Sabemos que a atividade do pensar é invisível e seus resultados visíveis, embora mostrem algo do pensar, não são iguais à atividade que antecede esse resultado.

Buscar compreender essa experiência do pensar que está escondida por trás de seus resultados é um dos caminhos que Arendt busca escolher para abordar essa atividade que é invisível. O problema, porém, reside no fato de "que poucos pensadores nos disseram o que os fez pensar, e um número ainda menor se deu ao trabalho de descrever e examinar a sua experiência de pensar." (ARENDT, 2004, p. 236).

Assim, a autora busca de alguma maneira, investigar o que fez essas pessoas pensarem e qual era a relação do pensar destes com o mundo. Entre os pensadores, estão aqueles que conviveram com a autora, como seus professores Heidegger e Jaspers, mas também Platão, Kant e, principalmente Sócrates. Temos,

\footnotetext{
${ }^{8}$ Seriam subprodutos incidentais do próprio pensamento.

Criar Educação, Criciúma, v. 7, no1, jan/jul 2018.- PPGE - UNESC
} 
pois não desejava transmitir respostas, mas procurava "compreender o mundo e queria fazer pensar." (ALMEIDA, 2011, p. 162).

Sobre Sócrates, Arendt (2004, p. 236) considera que o fato dele

[...] nunca tenha experimentado formular uma doutrina que pudesse ser ensinada ou aprendida. [...] proponho usar como nosso modelo um homem que realmente tenha pensado sem se tornar um filósofo, um cidadão entre os cidadãos, alguém que não tenha feito ou reivindicado nada além daquilo que, na sua opinião, todo cidadão devesse fazer e tivesse direito a reivindicar. Vocês terão adivinhado que pretendo falar de Sócrates.

Assim, há um princípio ao qual Arendt não abre mão: o ato de refletir sobre as experiências. O pensar é "vivo quando delas se alimenta, e morto quando começa a girar apenas em torno de si mesmo." (ALMEIDA, 2011, p. 164). Portanto, o que os mais diversos "modelos" de pensamentos tiveram em comum é justamente a procura de compreender o significado de nossas experiências.

Uma atividade que não tem um fim e que nos instiga a prosseguir, a procurar respostas para as questões que só podemos receber respostas provisórias. Mas, essa busca está intrinsicamente ligada a nossa capacidade de assumirmos a responsabilidade pelo mundo, pois, somente quando o mundo onde nós estamos e tudo o que acontece nele faz algum sentido para nós, ele deixa de ser um lugar inóspito e passa a ser a nossa casa, que precisa de nós para ser organizada, transformada, reformada e conservada.

A preocupação da educação escolar está justamente na relação entre a instabilidade do pensar e a continuidade do mundo, no qual precisamos familiarizar os novos a partir do seu legado, mesmo com a perda da tradição, ainda existe alguma coisa que necessita e merece ser preservada do esquecimento. Portanto, conhecer o mundo é parte fundamental da educação escolar, pensar sobre o mundo também é refletir sobre os conhecimentos que fazem parte dele. Pois, "à medida que os alunos se familiarizam com os saberes e as práticas desse espaço comum, tornar-se-ão capazes de assumir sua responsabilidade por ele.” (ALMEIDA, 2011, p. 38).

Portanto, conhecer o mundo não significa apenas ter acesso às informações sobre ele, pois para isso, não precisaríamos da escola hoje. O papel do educador é o de ser o mediador entre o mundo e os jovens, em outras palavras, é ir além de um Criar Educação, Criciúma, v. 7, no1, jan/jul 2018.- PPGE - UNESC 
"abrir portas", que poderia ser feito pelo professor de modo mecânico e até indiferente (ALMEIDA, 2011).

Seu papel de mediador the exige uma responsabilidade dupla ${ }^{11}$, ser responsável pela educação de seus alunos, mas também assumir a responsabilidade pelo mundo. Assim o professor não apenas apresenta, mas também representa o mundo diante dos recém-chegados.

Ainda em, José Sérgio F. Carvalho (2008, p. 21),

O acolhimento dos novos no mundo pressupõe, pois, um duplo e paradoxal compromisso do professor. Por um lado, cabe-lhe zelar pela durabilidade do mundo de heranças simbólicas no qual ele inicia e acolhe seus alunos. Por outro, cabe-lhe cuidar para que os novos possam se inteirar, integrar, fruir e, sobretudo, renovar essa herança pública que lhes pertence por direito, mas cujo acesso só lhe é possível por meio da educação.

Uma das conclusões que Arendt faz em seu ensaio, é que,

[...] a função da escola é ensinar às crianças o mundo como ele é, e não instruí-las na arte de viver. Dado que o mundo é velho, sempre mais que elas mesmas, a aprendizagem volta-se inevitavelmente para o passado, não importa o quanto a vida seja transcorrida no presente. (ARENDT, 2013, p. 246).

Ainda, segundo Morandi (2002, p. 39),

Há de se preservar a vida da criança - que ao nascer é frágil, impotente, desamparada - e cuidar de sua inserção na realidade sócio-histórica-cultural que a espera e, ao mesmo tempo, preservar o mundo, transmitir a tradição, as heranças culturais no sentido de garantir a continuidade do mundo.

Como representante do mundo, é tarefa do professor proteger e conservar, mostrando sua relevância para os novos. "Se sua qualificação consiste em seu conhecimento, sua autoridade frente aos recém-chegados reside nesse ofício de representante que o autoriza a introduzi-los neste lugar." (ARENDT, 2013, p. 239). É importante ressaltar que, é o lugar que o professor ocupa e sua tarefa específica que conferem a autoridade $^{12}$, que não se estende a outras esferas que vão além da escola.

\footnotetext{
${ }^{11}$ Aquele que educa, precisa proteger o mundo contra as crianças e as crianças contra o mundo. Nesse sentido, educar significa resguardar "o velho contra o novo, o novo contra o velho." (ARENDT, 2013, p. 242).

${ }^{12}$ É importante destacar que Arendt, distingue autoridade de certas formas de força e/ou violência. Mesmo que em ambos os casos podemos falar de uma relação hierárquica e de obediência, "aquele que obedece ao mais forte, $\mathrm{o}$ faz por medo ou por ser forçado fisicamente a obedecer, enquanto aquele que obedece à autoridade o faz Criar Educação, Criciúma, v. 7, no1, jan/jul 2018.- PPGE - UNESC
} 


\section{CRIAR EDUCAÇÃOO \\ Revista do Programa de Pós-Graduação em Educação - UNESC

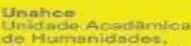

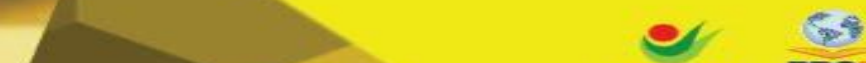

Não obstante, para os recém-chegados, que, na escola, se encontram nesse processo de conhecer o mundo, a aquisição dos saberes pode assim, estar voltada/relacionada à reflexão sobre o seu significado. Entretanto, não podemos nos equivocar e querer classificar as disciplinas escolares que promovem 0 conhecimento e as que fomentam o pensamento, como por exemplo, "química somente envolve conhecimentos e filosofia somente pensamentos". Contudo, "em maior ou menor grau, [...] todo assunto exige algum tipo de conhecimento dos alunos, como também [...] [que] sejam instigados a indagar-se sobre o seu possível significado ou a falta dele." (ALMEIDA, 2011, p. 184).

Assim, o conhecimento das disciplinas, a aquisição e produção desses conhecimentos, exigem a escolha dos alunos que dependem do pensamento e de nosso lugar no mundo e buscar compreender de que modo eles nos dizem respeito. Não devemos submeter as relações pedagógicas e os conteúdos curriculares à "tirania da verdade", pois estaríamos colocando em perigo os aspectos de um pensar que "vai além dos limites do conhecimento" (ALMEIDA, 2011).

Ademais, convidar os recém-chegados para essa atividade do pensar é um desafio para a educação escolar, vivemos em um tempo marcado pela "solidão", inabilitando a capacidade do pensar e significar o mundo, propiciando assim a banalidade. Educar para a atividade do pensar e ressignificar o mundo que habitamos é uma urgência.

Educar para a atividade do pensar requer a possibilidade nas nossas relações escolares, nas salas de aula e atitudes que possibilitem o que Arendt considera: "estar só" para o diálogo do "eu" consigo mesmo. Toda conversa realizada dialogicamente - professor/aluno, aluno/texto, alunos/alunos - deve conduzir ao silêncio, deve instigar os alunos para o diálogo consigo mesmo, ou seja, toda atividade realizada deve propiciar no educando, uma reflexão, significação pessoal e interna.

A atividade do pensar é assim, interrompe todas as nossas atividades, nos deixa inseguros no momento em que duvidamos sobre coisas que antes nos

por consentimento". (ARENDT, 2013, p. 129). Nesse sentido, o professor pode constituir uma autoridade frente ao aluno, "se ambos reconhecem a legitimidade do mundo comum e a necessidade de sua continuidade." (ALMEIDA, 2011, p. 39).

Criar Educação, Criciúma, v. 7, nำ, jan/jul 2018.- PPGE - UNESC 


\section{CRIAR EDUCAÇÃO \\ Revista do Programa de Pós-Graduação em Educação - UNESC}

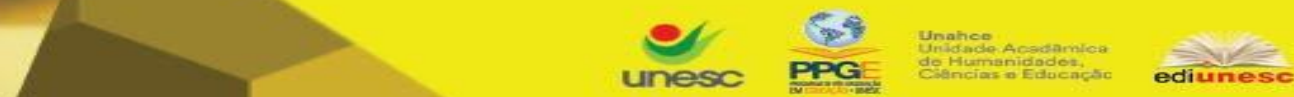

reconciliação, é por meio dele que aceitamos que o mundo está "fora dos eixos", que é nosso e que, portanto, nós somos responsáveis por ele e por nós, isto é, precisamos constantemente consertá-lo e renová-lo.

Segundo Fensterseifer (2005, p. 158), “[...] pertencemos e somos responsáveis [...] pela introdução dos jovens neste mundo, o qual, por estar em constante mudança, apresentará sempre novos desafios às novas gerações." Ademais, uma educação comprometida com a atividade do pensar, precisa introduzir a criança no mundo humano e deve contribuir para a capacidade de reflexão do próprio aluno, já que este não é capaz somente de adquirir conhecimentos, mas também de pensar e compreender as experiências humanas no mundo e refletir sobre seus significados.

\section{SOBRE A IMPORTÂNCIA DO COMUNICAR NA EDUCAÇÃO ESCOLAR}

Pensar segundo Arendt, é buscar o sentido. Mas, o que é o sentido? $\mathrm{Na}$ concepção arendtiana não existe um eu prévio no mundo, mas apenas um eu que se relaciona com o mundo. A pessoa é alguém, apenas na relação com os outros, logo, é na interação que surge o sentido. O sentido, pode se revelar nas histórias, pois é nas histórias que temos o elemento pessoal, são as histórias que nos contam de pessoas, de palavras, de preocupações, de feitos, de acertos e erros, em suma de suas experiências no mundo, é nas histórias que tudo isso entra em contato com todas as pessoas.

Ao contarmos uma história o sentido pode surgir de modo imediato, "pela experiência pessoal que a história narra." (ALMEIDA, 2011, p. 204). É na história que conseguimos perceber e reconhecer as nossas preocupações, as nossas tristezas, alegrias e as nossas lutas. Dessa forma, o sentido surge quando estabelecemos relações intersubjetivas, é a partir do comunicar que as experiências humanas dão testemunho, e os novos podem se reconhecer e assim são desafiados a pensar sobre o seu papel no mundo, logo, "ter linguagem significa ter mundo." (MARQUES, 1993, p. 92). 
Retomando Benjamin, "O Narrador" começa apresentando a volta de soldados da Primeira Guerra Mundial, todavia, os mesmos não eram mais ricos e sim mais pobres em experiência comunicável. Assim, os acontecimentos deixaram de ser histórias humanas, pois os homens já não desempenham nenhum papel neles. Sobrou apenas o "frágil e minúsculo corpo humano", que está jogado em um "campo de forças de torrentes e explosões." (BENJAMIN, 1986, p. 198).

Assim, Benjamin nos alerta que num mundo sem sentido, incapaz de estabelecer relações com os outros e com os acontecimentos, nós perdemos a capacidade de narrar/comunicar alguma história e também de agir, considerando que "a arte de narrar está em vias de extinção." (BENJAMIN, 1986, p. 197). Se o diálogo é negado, compromete, dessa forma, qualquer possibilidade de construir um processo humano que supere a situação atual em que nos encontramos (HABERMAS, 1998). Desse modo, não podemos desistir das histórias, ou segundo Arendt, não podemos abrir mão de uma atividade responsável em relação ao mundo.

O professor pode comunicar e compartilhar com seus alunos as experiências que fazem sentido para ele. As histórias não são relevantes por si mesmas, mas pelo fato de serem significativas para os mais velhos, podem ser ressignificadas pelos novos a partir do diálogo constante.

Para Boufleuer (1991, p. 119), existem momentos, "[...] em que o mestre escuta o discípulo, respeitando-o no que tem de novo e criador, como também, há um momento em que o discípulo escuta o mestre, buscando aprender o legado que ele tem a transmitir." Nessa direção, para Marques (1993, p. 108) “A educação é o alargamento do horizonte, cultural, relacional e expressivo, na dinâmica das experiências vividas e na totalidade da aprendizagem da humanidade pelos homens. Nela pessoas e grupos [...] confrontam-se no diálogo."

Nesse contexto, Arendt (1993, pp. 141-142) considera que "antes de conversar comigo mesmo, converso com os outros [...] e então descubro que eu posso conduzir um diálogo não apenas com os outros, mas também comigo mesmo." Não obstante, o professor deve se revelar na ação educativa, instigando os alunos a buscarem de maneira singular a relação com o mundo, não trata de querer 
mudar o mundo, mas sim compreendê-lo, para a possibilidade de uma futura ação neste mundo.

Não se ensinam ou aprendem coisas, mas relações estabelecidas em entendimento mútuo e expressas em conceitos, que, por sua vez, são construções históricas, isto é, nunca dadas de vez, mas sempre retomadas por sujeitos em interação e movidos por interesses práticos no mundo em que vivem. (MARQUES, 1993, p. 110, grifo nosso).

Portanto, educar é "colocar as coisas em relação", para que cada um possa e seja desafiado a buscar o sentido dessas coisas e descobrir a sua singularidade, 0 que o faz pertencer ao mundo, o nosso mundo.

\section{CONSIDERAÇÕES FINAIS}

A atividade do pensar e a prática de comunicar os pensamentos, está voltada à continuidade do mundo comum, com a qual a educação escolar deve estar preocupada. A capacidade de "parar para pensar", produz conhecimentos sobre o mundo que são de enorme importância para nos orientarmos e garantir uma estabilidade.

Todavia, esse lugar depende da nossa ação, para renovar, transformar e buscar um sentido, sentido este que não nos é apresentado de modo isolado, mas se forma a partir da nossa reflexão sobre os acontecimentos, fatos, saberes e conhecimentos sobre o mundo. A tarefa da educação escolar está em contribuir para que os recém-chegados possam se encontrar nele, possibilitando uma relação própria com esse lugar e seu legado a partir da atividade do pensar, pois, é a partir da reflexão sobre o mundo que ele passa a se tornar significativo.

Ademais, o desafio atual da educação escolar é tornar significativo aquilo que o professor comunica, evitar um pensamento passivo, buscar relações intersubjetivas, mediações a partir do diálogo, constituir a formação da subjetividade, isto é, indivíduos capazes de enfrentar as incertezas e constantemente reconstruir o conhecimento, para que seja possível acompanhar as rápidas transformações da historicidade contemporânea. 
Homens em tempos sombrios. Tradução de Denise Bottmann. São Paulo: Companhia das Letras, 2003.

. Entre o passado e o futuro. Tradução de Mauro W. Barbosa. 7. ed. São Paulo: Perspectiva, 2013.

Was bleibt? Es bleibt dia Muttersprache. In: REIF, Adalbert (Hg.). Gespräche mit Hannah Arendt. München: Piper, 1976.

A condição humana. Tradução de Roberto Raposo. Posfácio de Celso Lafer. 10.ed, Rio de Janeiro: Forense Universitária, 2010.

BENJAMIN, W. O narrador: considerações sobre a obra de Nikolai Leskov. In: Magia e técnica, arte e política: ensaios sobre literatura e história da cultura. Tradução de Sergio Paulo Rouanet. Prefácio de Jeanne Marie Gagnebin. 2.ed. São Paulo: Brasiliense, 1986. V. 1, pp. 197-221. (Obras escolhidas).

BOUFLEUER, J. P. Pedagogia latino-americana: Freire e Dussel. ljuí: Ed. UNIJUÍ, 1991.

CARVALHO, J. Hannah Arendt pensa a educação. Revista Educação. Coleção Especial: Biblioteca do Professor no 4. São Paulo: Editora Segmento, 2008.

FENSTERSEIFER, P. E. A responsabilidade social da educação escolar (ou "A escola como instituição republicana"). In: MASS, Adriana K.; ALMEIDA, Airton L.; ANDRADE, Elisabete (Orgs.). Linguagem, escrita e mundo. ljuí: Ed. UNIJUÍ, 2005.

HABERMAS, J. O Discurso Filosófico da Modernidade. $2^{\text {a }}$ ed. Lisboa: Dom Quixote, 1998.

MARQUES, M.O. Conhecimento e modernidade em reconstrução. ljuí: Ed. UNIJUÍ, 1993. (Coleção educação).

MORANDI, F. Filosofia da Educação. Tradução de Maria Emil P. Charnut. Bauru, SP: EDUSC, 2002.

ROUANET, S. P. As raízes do iluminismo. São Paulo: Cia. das Letras, 1987.

Recebido em setembro 2017

Aprovado em fevereiro 2018

Criar Educação, Criciúma, v. 7, no1, jan/jul 2018.- PPGE - UNESC 